\title{
Equipment
}

\author{
A. Yasodananda Kumar MD (Anaesth), \\ K. Bhavani-Shankar MD (Anaesth), \\ Harley S.L. Moseley FFARCS, Yvette Delph DA
}

\section{Inspiratory valve malfunction in a circle system: pitfalls in capnography}

\begin{abstract}
Capnography is a useful technique in monitoring the integrity of anaesthetic equipment such as the malfunctioning of unidirectional valves in circle system. However, the lack of a precise mechanism in existing capnographs to identify the start of inspiration and the beginning of expiration in the capnograms, makes the analysis of the carbon dioxide waveforms during inspiration difficult and thus results in inaccurate assessment of rebreathing. We report a case where, during the malfunction of the inspiratory unidirectional valve in the circle system, the capnograph failed to detect the presence of substantial rebreathing. Critical analysis of the capnogram recorded during the malfunction revealed that there was substantial rebreathing which was underestimated by the capnograph as it reports only the lowest $\mathrm{CO}_{2}$ concentration rebreathed during inspiration in such abnormal situations.
\end{abstract}

La capnographie peut être utile pour évaluer le fonctionnement de l'appareil d'anesthésie et en particulier des valves du circuit unidrectionnel. Cependent, pour les capnographes en usage présentement, l'absence d'un mécanisme approprié permettant d'identifier le début de l'inspiration et de l'expiration, rend difficile l'analyse de la courbe du gaz carbonique et peut faire rater l'apparition du rebreathing. Nous rapportons ici un incident au cours duquel, le capnographe a été dans l'impossibilité de détecter un rebreathing important causé par

\section{Key words}

EQUIPMENT: anaesthesia circuits;

MEASUREMENT TECHNIQUES: capnometry; MONITORING: carbon dioxide.

From the Department of Anaesthesia, Queen Elizabeth Hospital, University of West Indies, Faculty of Medical Sciences, Barbados, West Indies.

Address correspondence to: Dr. A.Y. Kumar.

Accepted for publication 9th July, 1992. le mauvais fonctionnement d'une valve unidirectionnelle $d u$ circuit anesthésique. Une analyse rétrospective du capnogramme enregistré pendant l'incident a montré un rebreathing considerable, sous-estimé par le capnographe, car cet appareil ne peut qu'afficher la plus basse concentration de $\mathrm{CO}_{2}$ réinspirée pendant l'inhalation, même dans une situation anormale telle que décrite.

Capnography is a graphic record of changes in the concentration of carbon dioxide $\left(\mathrm{CO}_{2}\right)$ in the respired gases during the respiratory cycle. In most capnographs the concentration of $\mathrm{CO}_{2}\left(\mathrm{FCO}_{2}\right)$ is plotted against time. There are several reports of the usefulness of capnographic waveforms in detecting malfunction of the unidirectional valves in the circle breathing system. ${ }^{1-3}$ It has been suggested that analysis of the $\mathrm{CO}_{2}$ waveform and its shape during inspiration would give more information about rebreathing during valve leaks. ${ }^{2}$ We report a case where capnography helped to identify inspiratory unidirectional valve malfunction during the course of anaesthesia. Analysis of the capnogram revealed that there was substantial rebreathing, although the capnograph did not sound any rebreathing alarm. The aim of this report is to emphasize the need to analyze the capnogram in relation to the events in the respiratory cycle and to determine the extent of rebreathing in the circle system in such abnormal situations.

\section{Case report}

A 45-yr-old lady (ASA physical status I) weighing $65 \mathrm{~kg}$ was scheduled for elective cholecystectomy. Anaesthesia was induced with thiopentone and maintained with halothane in oxygen $\left(2 \mathrm{~L} \cdot \mathrm{min}^{-1}\right) /$ nitrous oxide $\left(3 \mathrm{~L} \cdot \mathrm{min}^{-1}\right)$. Muscle relaxation was maintained with d-tubocurarine. An Ohmeda excel-210 anaesthetic machine and a semiclosed circle system with $\mathrm{CO}_{2}$ absorption (Ohmeda GMS circle absorber) were used. Controlled ventilation was performed with an Ohmeda 7000 ventilator $(f=12$, tidal volume 9 

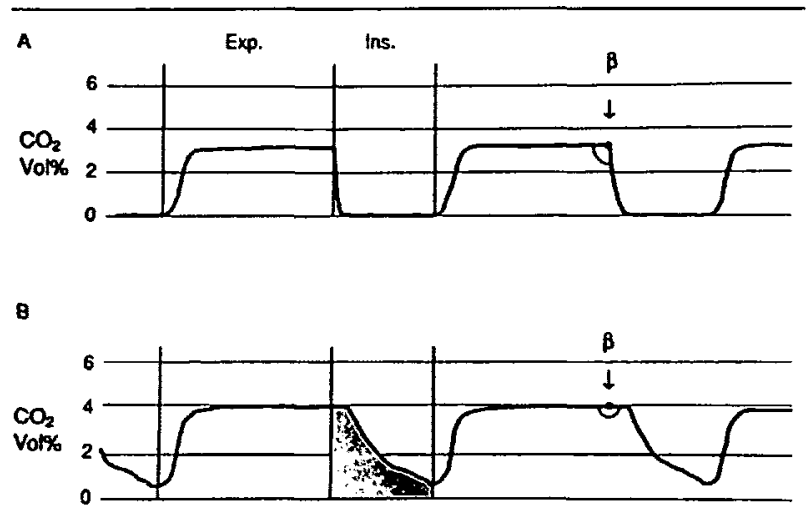

FIGURE 1 (A) Normal capnogram, $\mathrm{f}=12, \mathrm{FETCO}_{2}=3 \%, \beta$ - angle between expiratory plateau and inspiratory limb approximately equals $90^{\circ}$. (B) Abnormal capnogram recorded during malfunction of the inspiratory unidirectional valve, $\mathrm{f}=12, \mathrm{FETCO}_{2}=4 \%, \beta$ - angle between expiratory plateau and inspiratory limb equals $180^{\circ}$, shaded area represents rebreathing.

$\mathrm{ml} \cdot \mathrm{kg}^{-1}$ ). Respiratory rate, expired tidal volume and minute volume were monitored with an Ohmeda 5420 volume monitor, the sensor being placed between the corrugated tube and the expiratory unidirectional valve. The airway pressure was monitored by a pressure gauge mounted on the circle absorber. A Datex 245P monitor with printing facilities was used to monitor ECG, noninvasive blood pressure, $\mathrm{CO}_{2}$ waveform and oxygen saturation. During the course of an otherwise uneventful anaesthetic, a rising end-tidal $\mathrm{CO}_{2}$ concentration $\left(\right.$ FETCO $\left.{ }_{2}\right)$ and a change in the pattern of the capnogram were observed (Figure 1). The capnogram showed a prolonged plateau, an apparently short inspiratory period and a gradually sloping descending limb which stopped just short of baseline (Figure 1B). The capnograph did not sound the rebreathing alarm (set at $\mathrm{FICO}_{2}$ of $1 \%$ ). The peak inspiratory pressure remained unaltered. The tidal volume delivered to the patient appeared to be unchanged as indicated by movement of the bellows, peak inspiratory pressure and chest movement. However, the exhaled tidal volume measured by the volume monitor showed considerable reduction from $585 \mathrm{ml}$ to $325 \mathrm{ml}$. Inspection of the ventilator and the breathing circuits revealed that the inspiratory unidirectional valve was not functioning properly. The metal retainer, which maintains the position of the disc on the annular seat, had slipped from its position over the gas inlet within the unidirectional valve assembly. As a result the disc was displaced into the valve body, making the valve incompetent. The problem was rectified immediately. The capnogram reverted to a normal trace and $\mathrm{FETCO}_{2}$ returned to normal range. Subsequent anaesthesia proceeded uneventfully.

\section{Discussion}

One of the drawbacks of existing capnographs $\left(\mathrm{FCO}_{2}\right.$ vs time) is that there is no mechanism to identify the beginning of inspiration or expiration. It is assumed that inspiration begins at the end of the alveolar plateau (phase III) and the descending limb reflects inspiration. ${ }^{4}$ The angle between the alveolar plateau and the descending limb (designated as $\beta$ in Figure IA) is approximately 90 degrees. However, these assumptions are not true in the abnormal situation described in the case report. Therefore we compared the abnormal capnogram recorded during malfunction of the inspiratory unidirectional valve with the normal capnogram to determine the relationship between the $\mathrm{CO}_{2}$ waveform and the components of respiratory cycle. As there were no differences in the ventilatory variables (minute volume, respiratory frequency, I:E ratio) during the recording of the capnograms, the abnormal capnogram was compared with the normal by aligning the beginning of phase II of both curves. The line marking the end of phase III in the normal capnogram was then extrapolated onto the abnormal capnogram to identify the beginning of inspiration (Figure 1). Thus the part of alveolar plateau after phase III in the abnormal capnogram represents a part of inspiration. The angle between expiratory limb and inspiratory limb is now 180 degrees (angle $\beta$ in Figure 1B). The shaded area in the abnormal capnogram indicates the extent of rebreathing (Figure 1B).

When the inspiratory unidirectional valve in the circle system is incompetent, exhaled gases enter the inspiratory limb of the circuit (Figure 2) and during the next inspiration, enter the lungs to produce prolonged $\mathrm{CO}_{2}$ plateau. These events result in a characteristic capnogram comprising an apparently shorter inspiratory phase and a prolonged expiratory plateau. ${ }^{2,3}$ Further, the flow of exhaled gases into the inspiratory limb results in a reduction in the expired tidal volume as measured between the expiratory limb and expiratory unidirectional valve.

The capnograph did not sound the rebreathing alarm for two reasons. First, the capnograph has no mechanism of identifying the beginning of inspiration and perceives the higher $\mathrm{FCO}_{2}(=\mathrm{FETCO})$ in early inspiration as a part of expiratory plateau. Second, the inspiratory slope came very close to the baseline and the minimum $\mathrm{FICO}_{2}$ was within the $1 \% \mathrm{CO}_{2}$ rebreathing limit set in the capnograph. We consider that the $\mathrm{FICO}_{2}$ as reported during dysfunction of the unidirectional valves in previous studies ${ }^{2,5}$ reflected the lowest concentration of $\mathrm{CO}_{2}$ rebreathed and hence underestimated the degree of rebreathing.

However, if it were possible to identify the start of inspiration, the inspiratory $\mathrm{CO}_{2}$ waveform could be analyzed to predict the extent of rebreathing. The computer algorithm described by van Genderingen et al. ${ }^{3}$ 


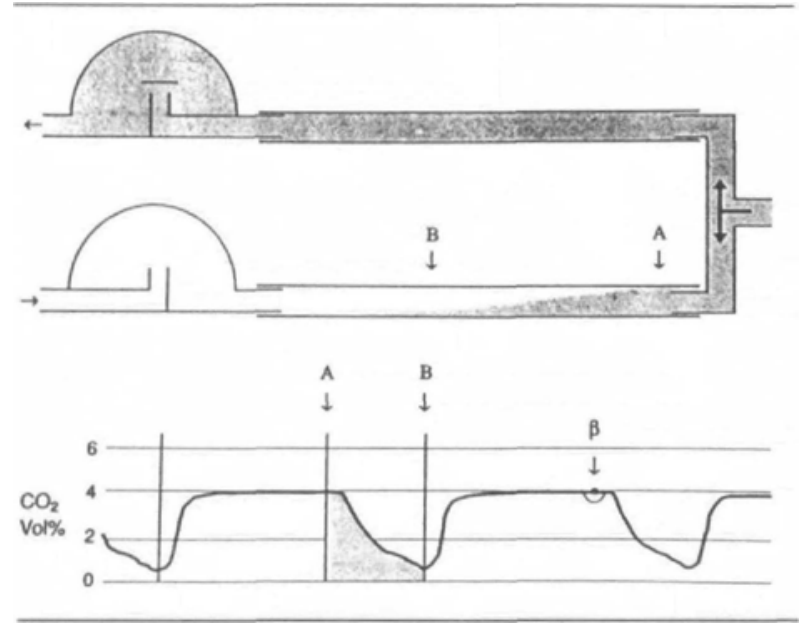

FIGURE 2 Diagrammatic representation of rebreathing pattern in circle system at the beginning of inspiration and the abnormal capnogram recorded during the malfunction of inspiratory unidirectional valve. Shaded area in circle system represents alveolar gases. (A) Alveolar gases rebreathed at the beginning of inspiration. (B) Beginning of phase II of expiration.

which analyzes the capnograms and identifies the abnormal by comparing it with the previously learned normal capnogram may be helpful in these circumstances but is impractical for routine $\mathrm{CO}_{2}$ monitoring. We suggest that the incorporation of spirometry into the capnographs to display the inspiratory and expiratory flow rate curves during a respiratory cycle in relation to a capnogram will enable a more appropriate analysis of $\mathrm{CO}_{2}$ waveforms to be performed in relation to the components of respiratory cycle. This will enhance the efficacy of capnography in identifying defective breathing systems.

\section{References}

1 Pyles ST, Berman $L S$, Modell JH. Expiratory valve dysfunction in a semiclosed circle anesthesia circuit verification by analysis of carbon dioxide waveform. Anesth Analg 1984; 63: 536-7.

2 Berman LS, Pyles ST. Capnographic detection of anaesthesia circle valve malfunctions. Can J Anaesth 1988; 35: 473-5.

3 van Genderingen $H R$, Gravenstein N, van der Aa JJ, Gravenstein JS. Computer-assisted capnogram analysis. J Clin Monit 1987; 3: 194-200.

4 Weingarten $M$. Respiratory monitoring of carbon dioxide and oxygen: a ten-year perspective. J Clin Monit 1990; 6: 217-25.

5 Podraza AG, Salem MR, Joseph NJ, Brenchley JL. Rebreathing due to incompetent unidirectional valves in the circle absorber system. Anesthesiology 1991; 75: A422. 